\title{
The symptomatic and objective effects of nifedipine in combination with beta- blocker therapy in severe angina pectoris
}

\author{
R. M. JENKINS* \\ M.R.C.P. \\ R. E. NAGLE \\ F.R.C.P. \\ Department of Cardiology, Selly Oak Hospital, Raddlebarn Road, Selly Oak, Birmingham B29 $6 J$ D
}

\begin{abstract}
Summary
Nine patients with severe coronary artery disease and disabling angina receiving either regular metoprolol or oxprenolol, together with glyceryl trinitrate tablets as required for chest pain, were studied. Nifedipine 10 mg three times per day was compared to placebo in a double blind randomized control trial, using patient diary cards and exercise tests.

The number of recorded episodes of angina during the placebo period of $15 \cdot 0 \pm 2 \cdot 1$ (mean \pm s.e.m.) per patient per week was significantly reduced to $11.2 \pm 2.5$ during the nifedipine period $(P<0.05)$. Similarly, the recorded number of glyceryl trinitrate tablets consumed during the placebo period of $12 \cdot 6 \pm 2 \cdot 1$ was significantly reduced to $9 \cdot 1 \pm 2 \cdot 0$ tablets per patient per week during the nifedipine period $(P<0.05)$.
\end{abstract}

There was a statistically significant increase in both the duration of exercise to onset of chest pain (from $241 \pm 16.3$ seconds on placebo to $306 \pm 38.4$ seconds on nifedipine $(P<0.05)$ ) and the total work performed to the onset of chest pain during the nifedipine period compared to the control and placebo periods $(P<0.05)$.

There was a significant increase $(P<0.05)$ in exercise time before the onset of appreciable ST depression $(>1 \mathrm{~mm})$ on exercise testing during the nifedipine period $(66.2 \pm 4.2 \mathrm{sec})$ compared to the control period $(51 \cdot 2 \pm 3.0 \mathrm{sec})$ and placebo periods $(58.7 \pm 3.5 \mathrm{sec})$.

Although nifedipine was generally well tolerated, one patient experienced a severe episode of angina whilst taking the drug, which required admission to hospital.

\section{Introduction}

Beta-adrenergic blocking agents have been shown to reduce both the frequency of chest pain and

\footnotetext{
*Present address: Department of Medicine, Queen Elizabeth Hospital, Birmingham B15 2TH.
}

glyceryl trinitrate consumption in patients with angina pectoris, and also to increase the amount of pain-free work and total amount of work performed on exercise testing (Coltart, 1972; Elliot and Stone, 1969; George, Nagle and Pentecost, 1970; Jorgensen et al., 1973; Keyrilainen and Uusitalo, 1976; Prichard and Gillam, 1971). Some patients, however, continue to experience incapacitating angina and may require additional anti-anginal therapy.

We have investigated the addition of the calcium antagonist nifedipine, in patients who continue to experience disabling angina despite the use of betablocking agents and glyceryl trinitrate tablets. We were particularly interested to compare the subjective and objective effects of this combination.

\section{Patients and methods}

Nine males with severe stable angina were studied. Their ages ranged from 44 to 62 years and the duration of angina from 6 months to 11 years. All were taking either metoprolol (100-400 mg daily) or oxprenolol (240-320 mg daily) together with glyceryl trinitrate tablets as required. Throughout the trial the dosage of beta-blockers for each patient remained unchanged and glyceryl trinitrate tablets were taken only for the relief of chest pain. Seven of the nine patients had coronary angiography performed which showed three vessel disease. Patients were initially assessed by diary cards and two exercise tests performed at least three days apart. Those patients who experienced at least one episode of angina per day and who manifested clearly defined and reproducible chest pain on exercise during the control period were entered randomly in a double blind fashion into a 2-week period in which they received either nifedipine $10 \mathrm{mg}$ three times per day or an identical capsule of placebo three times per day, followed by a cross over after each initial 2-week period. The number of episodes of chest pain and glyceryl trinitrate consumption during the second week of 
each treatment period were recorded, and during the same second week two exercise tests were performed at least three days apart, the second of which was used for comparison between the treatment groups. Statistical analysis was performed by the Student's paired $t$-test.

Exercise testing was performed using a bicycle ergometer commencing at a work load of 20 watts and increasing by increments of 10 watts per minute. Blood pressure and heart rate were measured every minute and a continuous electrocardiograph monitored the onset and degree of ST segment depression. Patients were asked to indicate the onset of chest discomfort and to continue the exercise until stopped either by intolerable chest pain, breathlessness or fatigue.

\section{Results}

Most patients benefitted symptomatically from the addition of nifedipine, experiencing a significant reduction in both the number of episodes of chest pain and of glyceryl trinitrate consumption (Table 1). The response, however, was not uniform and the extent of the response varied quite considerably between each individual.
Comparing the initial two control exercise tests performed whilst patients were taking beta-blockers and glyceryl trinitrate only, there was no significant difference in the duration of exercise before the onset of chest pain, in the total duration of the exercise test or in the total work performed at either the onset of chest pain or to the termination of exercise.

The duration of exercise in seconds to the onset of chest pain and the total amount of work performed to the onset of chest pain were significantly increased during the nifedipine period compared to the placebo and control periods, $(P<0.05$, Table 2 , Figs. 1 and 2$)$. However, the total duration of exercise in seconds and the total amount of work performed to the end of exercise testing, were not significantly increased during the nifedipine period compared to the placebo period. There was a correlation between reduction in episodes of angina and the response to exercise testing. Five patients showing over a $30 \%$ reduction in the number of episodes of chest pain experienced an increase in the duration of the exercise test before the onset of chest pain by at least one minute.

There was a significant delay to the onset of ST segment depression during the nifedipine period of $66 \cdot 2 \pm 4 \cdot 2 \mathrm{sec}$ compared to the control period of

TABLE 1. Comparison of symptomatic responses during control, placebo and nifedipine periods

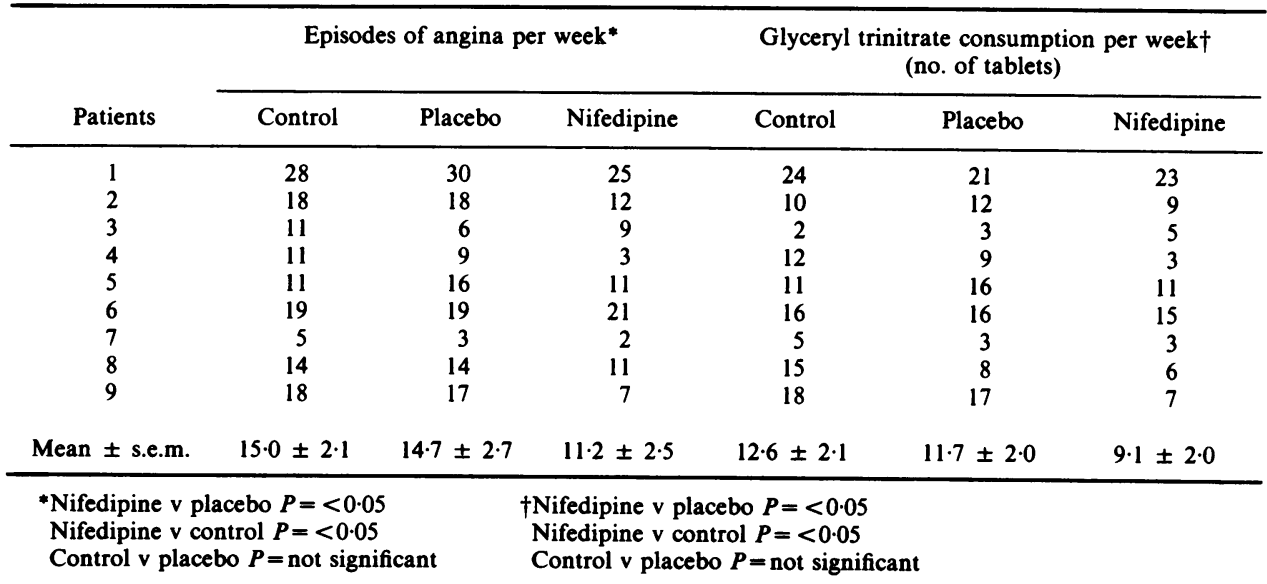

TABLE 2. Comparison of responses to exercise testing during control, placebo and nifedipine periods

\begin{tabular}{lcccccc}
\hline & & & & & $P$ values \\
\cline { 3 - 6 } & $\begin{array}{c}\text { Control } \\
\text { (a) }\end{array}$ & $\begin{array}{c}\text { Placebo } \\
\text { (b) }\end{array}$ & $\begin{array}{c}\text { Nifedipine } \\
\text { (c) }\end{array}$ & avb & avc & bvc \\
\cline { 2 - 7 } $\begin{array}{l}\text { Duration of exercise (secs) } \\
\text { to onset of chest pain } \\
\text { to end of exercise }\end{array}$ & $242 \pm 33^{*}$ & $241 \pm 16$ & $306 \pm 38$ & NS & $<0.05$ & $<0.05$ \\
& $349 \pm 23$ & $386 \pm 30$ & $411 \pm 38$ & $<0.05$ & $<0.05$ & NS \\
$\begin{array}{l}\text { Total work performed (watts) } \\
\text { to onset of chest pain } \\
\text { to end of exercise }\end{array}$ & $9578 \pm 1881$ & $8328 \pm 970$ & $15561 \pm 4010$ & NS & $<0.05$ & $<0.05$ \\
\hline Mean \pm s.e.m & $15733 \pm 1561$ & $18563 \pm 2094$ & $22594 \pm 3117$ & $<0.05$ & $<0.05$ & NS \\
\hline
\end{tabular}




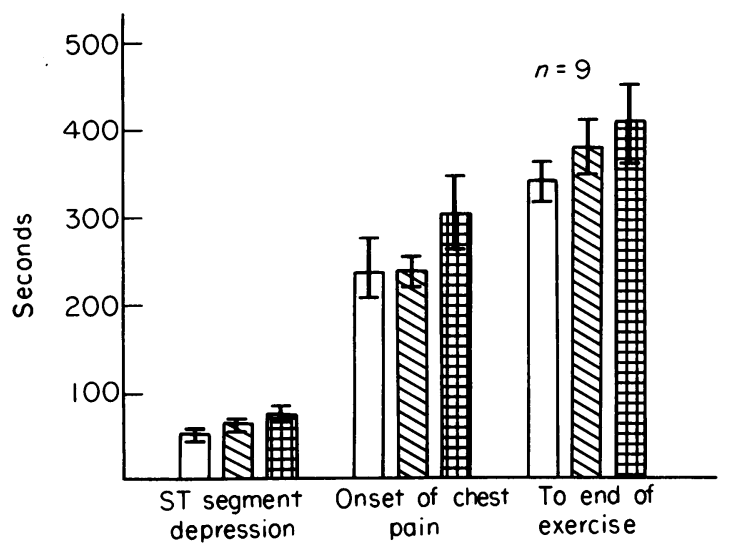

FIG. 1. Duration of exercise (secs) to ST segment depression, onset of chest pain and end of exercise in control, placebo and nifedipine periods (mean \pm s.e.m.); $\square$ control; $\mathbb{S}$ placebo; (业) nifedipine.

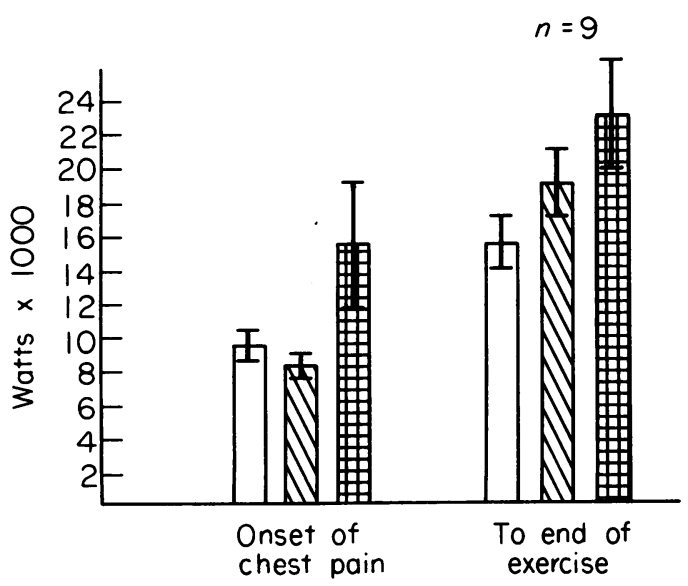

FIG. 2. Total work performed (watts) to onset of chest pain and end of exercise during control, placebo and nifedipine periods (mean \pm s.e.m.); $\square$ control; ( $(\mathbb{I V}$ placebo; (隹) nifedipine.

$51 \cdot 2 \pm 3 \mathrm{sec}$ and the placebo period of $58 \cdot 7 \pm 3 \cdot 5 \mathrm{sec}$ $(P<0.05$, Fig. 1).

Both systolic and diastolic resting blood pressures were reduced during the nifedipine period compared to the placebo period but the difference did not reach conventional levels of statistical significance. There was no significant difference in resting heart rate in the treatment periods.

One patient experienced a severe episode of angina within several hours of taking nifedipine during the seventh day of treatment which required admission. This patient also sustained the most marked fall in resting blood pressures within the group. Another patient experienced a gradual fall in exercise tolerance over the six consecutive exercise tests during the study and was admitted shortly after for coronary bypass grafting.

\section{Discussion}

Nifedipine is one of the most potent calcium channel blocking agents known and inhibits the slow inward current of calcium into the myocardial cell (Antman et al., 1980). Although it has been shown to increase myocardial oxygen supply by a coronary vasodilator effect (Fleckenstein, 1977) and has been particularly effective in coronary artery spasm (Muller and Gunther, 1978) its main action in classical angina pectoris may well be by an extra cardiac effect (Moskowitz et al., 1979).

The double product (blood pressure $\times$ heart rate) at both the onset of chest pain and the end of the exercise was similar during the nifedipine and placebo periods. This indicates that any improvement in exercise capacity was due to a reduced oxygen demand rather than an augmented myocardial oxygen supply, which was probably the result of a reduction in cardiac after-load secondary to a decrease in systemic vascular resistance induced by nifedipine (Lynch et al., 1980).

Clinically nifedipine produced a statistically significant reduction in the number of episodes of angina and of glyceryl trinitrate consumption and was appreciated by most of the patients as being of real clinical benefit. However, on exercise testing the drug produced a greater increase in pain free exercise and total work attainable before chest pain than in total exercise time and total exercise capacity. Thus, an improvement in the amount of pain-free work on exercise may be the more important determinant of clinical response. As the placebo and nifedipine period were randomized, five patients entering the active period initially and four the placebo period initially, it seems unlikely that any difference between these two periods was due to a training effect.

Most patients increased their exercise time before the onset of chest pain from an average of 4 to $5 \mathrm{~min}$ (28\%). If expressed as total work performed at the onset of chest pain the average increase appears greater $(87 \%)$ because the extra time before the onset of chest pain during a graduated exercise test is associated with a higher load of work as the exercise test proceeds.

Whereas there was no difference in time or work to the onset of chest pain between the control and placebo periods, total maximum work capacity did show an increase between control and placebo periods which nifedipine increased further by only a small amount. This significant increase in total exercise time and maximal work performed between the control and placebo period is difficult to explain. It may represent a training effect most pronounced 
between the initial control period and the other two periods that always followed. Alternatively, although both the onset of chest pain and the point of exhaustion are subjective end points, the latter point may be the less definable, more subjective and more susceptible to a placebo effect.

The study does show that quite small increases in measured work capacity may be associated with clinically significant benefits.

Interestingly, a severe exacerbation of angina during the nifedipine period occurred in one patient who also sustained the greatest hypotensive effect on the drug. Prolonged episodes of severe chest pain during nifedipine therapy have been well documented and although usually a first dose phenomenon can occur during the first week of treatment (Jariwalla and Anderson, 1978; Keider et al., 1980; Rodger and Stewart, 1978), it has not previously been recognized in association with a pronounced hypotensive response to nifedipine. However, it is possible that in the face of a fixed severe obstructive lesion of a coronary vessel, too drastic a reduction in systemic arterial pressure might compromise myocardial oxygen supply and cause an exacerbation of angina in some patients.

A difficulty in interpretation of the results of trials assessing anti-anginal therapy on the background of the varying natural history of coronary artery disease is well illustrated by the only patient to experience a reduction of exercise tolerance during the exercise tests while on nifedipine. However, his deterioration was gradual over six consecutive exercise tests and probably reflected the natural history of his severe disease.

The combination of a beta-blocker and nifedipine in the treatment of angina pectoris has several theoretical advantages. Any tendency towards a reflex tachycardia secondary to the hypotensive effect of nifedipine might be expected to be inhibited by the concurrent use of a beta-blocker. Secondly, the slight electrophysiological effect of nifedipine compared with other calcium antagonists would seem an advantage when combined with beta-blockers.

Although both drugs have slight negative ionotropic effects, there are very few reports of this combination being clinically detrimental (Opie and White, 1980; Anastassiades, 1980).

We found the combination of nifedipine with a beta-blocker useful and beneficial even in patients with severe coronary artery disease and disabling angina. The response, however, is variable, being good in most patients but not appreciable in others. The drug was generally well tolerated and most patients continued to use it.

\section{Acknowledgments}

We thank Mrs S. B. Cresswell and Mr J. Davies, Chief Physiological Technicians in Cardiology for their technical assistance, and Bayer UK Limited for kindly providing the active and placebo capsules.

\section{References}

ANASTASSIADES, C.J. (1980) Nifedipine and beta-blocker drugs. British Medical Journal, 281, 1251.

Antman, E.M., Stone, P.H., Muller, J.E. \& Braunwald, E. (1980) Calcium channel blocking agents in the treatment of cardiovascular disorders. Annals of Internal Medicine, 93, 6, 875.

COLTART, J.J. (1972) Observations on exercise tolerance in anginal patients treated with beta-blockers. International CIBA Symposium, Aarhus, Denmark.

Elliot, W.C. \& STONE, J.M. (1969) Beta-adrenergic blocking agents for the treatment of angina pectoris. Progress in Cardiovascular Disease, 12, 83.

FLECKENSTEIN, A. (1977) Specific pharmacology of calcium in myocardium, cardiac pacemaker, and vascular smooth muscle. Annual Review of Pharmacology and Toxicology, 17, 149.

George, C.F., NAGle, R.E. \& Pentecost, B.L. (1970) Practolol in treatment of angina pectoris. A double blind trial. British Medical Journal, 2, 402.

Jariwalla, A.G., ANDERSON, E.G. (1978) Production of ischaemic cardiac pain by nifedipine. British Medical Journal, 1, 1181.

Jorgensen, R.C., WaNG, K., WANG, Y., Gobel, F.L., Nelson, R.R. \& TAYLOR, H. (1973) Effect of propranolol on myocardial oxygen consumption and its haemodynamic correlates during upright exercise. Circulation, 48, 1173.

Keider, S., Marmor, A., Granadier, E. \& Palant, A. (1980) Nifedipine and Prinzmetil's angina. Circulation, 59, 1, 195.

Keyrilainen, O. \& Uusitalo, A. (1976) Effects of metoprolol in angina pectoris. Acta Medica Scandinavia, 199, 491.

LyNCh, P., Dargie, H., KRIKleR, S. \& KRICKLeR, D. (1980) Objective assessment of antianginal treatment: a double blind comparison of propranolol, nifedipine and their combination. British Medical Journal, 280, 184.

Moskowitz, R.M., Piccine, P.A., NACWelli, G. \& Zelis, R. (1979) Nifedipine for stable angina pectoris: preliminary result of effects on angina frequency and treadmill exercise response. American Journal of Cardiology, 44, 811.

MULLER, J.E. \& GUNTHER, S.J. (1978) Nifedipine therapy in Prinzmetil's angina. Circulation, 57, 137.

OPIE, L.H. \& WHITE, D.W. (1980) Adverse interaction between nifedipine and beta-blockade. British Medical Journal, 281, 1462.

Prichard, B.N.C. \& GillaM, P.M.S. (1971) Assessment of propranolol in angina pectoris. British Heart Journal, 33, 473.

RODGER, C. \& STEWART, A. (1978) Side effects of nifedipine. British Medical Journal, 1, 1612. 